\title{
Food wastes and food security: The case of Malaysia
}

\author{
Innocent A. Jereme ${ }^{1}{ }^{*}$, Chamhuri Siwar ${ }^{1}$, Rawshan Ara Begum ${ }^{2}$, Basri Abdul ${ }^{3}$ \\ 1Institute of Environment and Development (LESTARI), National University of Malaysia (UKM), Bangi 43600, Selangor D.E, \\ Malaysia \\ 2Institute for Climate Change, National University of Malaysia (UKM), Malaysia Bangi 43600, Selangor D.E, Malaysia \\ ${ }^{3}$ Faculty of Business and Economics, National University of Malaysia (UKM), Malaysia, Bangi 43600, Selangor D.E, Malaysia
}

\section{ARTICLE IN F O}

Article history:

Received 2 December 2016

Received in revised form

3 May 2017

Accepted 3 June 2017

\section{Keywords:}

Food wastes

Food insecurity

Food security

Households

Sustainable food waste management

\begin{abstract}
A B S T R A C T
Wasting foods is an affront to those in food insecurity. While thousands of these groups are in dare need of nutritious edible foods, households and restaurants alike are dumping large volumes of edible food wastes into waste bins on daily basis. The objectives of this study are to understand the need to use these large quantities of edible food wastes generated on daily basis by households, restaurants and hotels to reduce food insecurity among the poor households, the homeless and its other social impacts in Malaysia. This is because according to the Ministry of Housing and Local Government Malaysia (MHLG), households food wastes volume alone is up to 8,745 tons/per day amounting to 3,192,404 tones/per year. These represent more than 38.32 percent of all total wastes generated: while restaurants generate 941,608 tones/per year, 23.35 percent. However, despite this wastage in Malaysia, previous studies on food security have shown that people in urban low-income households indicated prevalence of overall food insecurity at $65.7 \%$ to $66.6 \%$ respectively than $58 \%$ reported in the rural low-income communities. It is therefore imperative to the channel these foods through the establishment of food banks in some affluent and strategic location in the cities to reduce food insecurity and its environmental and social impacts on the society. Wasting foods have social, environment and economic impacts, and at the same time negates the effort towards sustainable food consumption which has for the last two decades becomes everyday discussions of societies at large.
\end{abstract}

(C) 2017 The Authors. Published by IASE. This is an open access article under the CC BY-NC-ND license (http://creativecommons.org/licenses/by-nc-nd/4.0/).

\section{Introduction}

Global food wastage is a threat to food security, and it should be an issue of serious concern to any country that has the interest of her citizen at heart. This is because while tones of edible foods waste are lost/wasted during harvesting and production: at household's level, throwing away edible food wastes is also a common behaviour to behold in most affluent households in urban cities. However, with this pathetic wastage situation, still there abound thousands of households finding it difficult to have daily square meals in most urban and rural areas (food insecurity). It is very disheartening to see how edible foods are thrown away and healthy looking young kids are scrambling to get a better part of it to feed their empty stomach at some waste

\footnotetext{
* Corresponding Author.

Email Address: innocent_jereme@yahoo.com (I. A. Jereme) https://doi.org/10.21833/ijaas.2017.08.002

2313-626X/C 2017 The Authors. Published by IASE.

This is an open access article under the CC BY-NC-ND license

(http://creativecommons.org/licenses/by-nc-nd/4.0/)
}

bins/landfills in some parts of developing countries. Food wastes could be said to be a missed opportunity to improve the food security of those that are in the food insecurity globally. According to FAO (2007) people without enough food to put on their tables continue to grow at a very high rate amidst high wastage of food. It is estimated at over 800 million; surprising this number continues to grow amidst growing populations. Undernourished people amounts to over $60 \%$ of the world population of which the bulk of these people lives in Asia and Africa constituting about 49\%. Six million children die of hunger every year, 17,000 every day (FAO, 2007).

Per definition, food security just like the word "love" means different things to different people. However, FAO defines food security as when all people, at all times, have physical and economic access to sufficient, safe and nutritious food to meet their dietary needs and food preferences for an active and healthy life". Food security is known to have three main pillars, and the stability of these three pillars determines the strength of food security 
in any place which are these: i. Availability; Food security involves the availability of good quality, nutritious food from local, regional and international sources. ii Access: involves the physical and economic access to enough food for an active healthy life, iii. Stability: involves the stability of food supplies (availability), access to that food and the utilization of food consumed.

Anything that interrupts food supply and access or interferes with the utilization of food will lead to food insecurity and the amount of food that is wasted each year. Food wastes remains a large factor contributing to food insecurity around the world, but consumers can help reduce this by practicing a sustainable life style.

According to United States Department of Agriculture (USDA) in their study of food security in development countries for the coming decades, It estimated that about 882 million people will fall into the food insecurity groups, meaning the inability to have access to food that will give them adequate nutrition value for healthy living. The USDA estimated that people who will be food-insecure are estimated to rise in 76 countries in 2012 to 704 million to 707 in the year 2013. In some countries food riots have been reported taken place on daily basis especially in war torn areas and flood prone countries. There is growing concern as this has deprived many of nutritious foods which could jeopardize effort of many countries for a good healthy life style for their citizens.

Yet despite this frightening figure, more than one third of the foods that are produced today for consumption are lost or wasted either at production or at households (FAO, 2007). In the middle of 2013 British known grocery chain Tesco revealed from their data on food wasted across its supply chains in various stores. This startling revelation found that up to $68 \%$ of their salads were wasted before it is consumed. In the Sub-Africa, food wastes amount up to $150 \mathrm{~kg}$ per person which could help feed good number of people according to FAO study. It further stated that a third of foods currently produced are never consumed or reaches the plates of households. These amounts to $1.3 \mathrm{bn}$ tons of waste, a $£ 470 \mathrm{bn}$ economic loss and 3.3bn tones of $\mathrm{CO}_{2}$ emission which contributes to climate change globally every year and thus affect food security. The irony of it all is that despite this high wastage, the world needs an estimated $50 \%$ more food to feed a fast growing population by 2030 .

Food insecurity is not synonymous with the developing countries alone; in fact developed countries are also facing the same problem, they are not immune to this issue. In US with its prosperity is also food insecure, as 50 million people are facing food insecurity. For example, from a recent study it was found that households' in District of Columbia (D.C) is facing food insecurity at a very high rate than the national average at about $11.1 \%$, as against the $9.7 \%$ the whole country of the US. Even though the US is one of the largest foods producing countries in the world, yet one out of six people is "food insecure" including children according to the US Department of Agriculture. Yet it is estimated that about $30 \%$ of all foods thrown away amount to about US $\$ 48.30$ billion. At the farm level food wastes account to approximately 15 - 35\%. The retail shops experience more food wastes than farm as this stand at $25 \%$, while the super markets loss lesser at only $1 \%$. Total unconsumed food wastes amount to around US\$90100 billion per year. This is even higher than the entire budget of some developing countries, which is a social injustice as large numbers of people globally are food insecure. Food wastes has deprived many of nutritious food as prices of food become higher when demand outstrips supplies due to poor storages facilities mostly from developing countries and which leads to low supply. In some situation foods wasted are not accounted for due to nonchalant attitude towards the issue. According to Gustavsson et al. (2011) Europe and North America have the largest share of food wastes followed by industrial Asia and Latin America at households per kg/year. While Sub-Sahara Africa, North Africa, and Central Asia and South East Asia countries waste lesser at per capital levels. Large volumes of edible food wastes are being dump into landfills, and in some cases open dump fields in these regions, while many families are going hungry in the midst of plenty. This thereafter leads to pollution of the environment and underground water through leachates due to poor maintenance of the landfills. And when this happens, different diseases, such as respiratory ailments, reproduction abnormalities and skin ailments could become the order of the day in these areas.

\section{Food wastes in Malaysia}

In Malaysia the situation of food waste is not different, according to Ministry of Housing and local Government (MHLG) household's food waste volume stand at 8,745 tonnes/day, which is $3,192,404$ tones/per year, representing more than $38.32 \%$ of all total waste generated more than restaurants which generates 941,608 tones/per year, $23.35 \%$. An interview conducted by The Star Online reporter quoted a restaurant operator estimated that 10 to $30 \%$ of foods are wasted on an average daily in Malaysia, and most consumers are not aware or even concern of the amount of food they waste. According to this reports, when they were asked why they didn't finish the foods served, most of them will replied, they can't finish it but why do you care as the food was paid for (Loo, 2011). But this is quite different from some developed and industrialized countries. In some of these countries there exist many practices that could be learning with regard to food waste reduction generally. Many of these nations have already initiated plans to minimize food wastage.

In Japan for example, many restaurants in Tokyo are adopting a new approach in reducing food waste by offering customers a choice for food portions. If you order standard size of rice the restaurant will 
charge you at normal price. However, if you want to order a smaller portion, that is if you are certain that you are unable to finish standard size portions, the eatery will give a discount of about 50 Yen. From the observation if you ask for a bigger portion, you will get that at no extra cost from the findings. With this strategy they could put a check on foods serve to customers. With such a touch of creativity, the issue of food waste was minimized effectively in Japan. This is an incentive to customers to reduce food wastes and encourage them that such attitude is appreciated there (Loo, 2011).

Restaurants and food outlets in Malaysia that are green conscious could encourage their costumers to reduce food waste; by applying such system and puts a check on food wastage. But this could only be possible where there are strong policy regulations on food waste management by the government. Food wastage has reached to alarming rate amidst high cost of foods, as recently food subsidy was removed from some certain foods stuff which leads to more food insecurity in the society. This is because from observation some Malaysians consume foods more than the traditional three square meals per day obtained in other parts of developed and developing countries (Jereme et al., 2016). Some consumes up to four to five times of meal per day. With the level of food wastes at households and restaurants, Malaysia was close to a developed country status in the amount of food wastes generated as compared to other developing Asia nations which had almost zero unconsumed foods (Agamuthu, 2011). Table 1 shows the current solid waste composition in Malaysia. Food waste was higher from 2002 to 2010. In fact in 2003 it constituted more than $50 \%$ of the total food waste generated that whole year.

Table 1: Municipal solid waste composition in Malaysia

\begin{tabular}{|c|c|c|c|c|c|c|c|}
\hline Components & $2002 \%$ & 2003 & 2004 & 2005 & 2006 & 2007 & $2010 \%$ \\
\hline Food waste & 32 & 56.3 & 37.4 & 49.3 & 45 & 42 & 43.5 \\
\hline Mixed plastic & 16 & 13.1 & 18.9 & 9.7 & 24 & 24.7 & 25.2 \\
\hline Mix paper & 29.5 & 8.2 & 16.7 & 17.1 & 7 & 12.9 & 22.7 \\
\hline Textiles & 3.4 & 1.3 & 3.4 & --- & -- & 2.5 & 0.9 \\
\hline Rubber and leather & 2 & 0.4 & 1.3 & -- & -- & 2,5 & -- \\
\hline Wood & 7 & 1.8 & 3.7 & -- & -- & 5.7 & -- \\
\hline Yard wastes & -- & 6.9 & 3.2 & -- & -- & -- & -- \\
\hline Ferrous & 3.7 & 2.1 & 2.7 & 2 & 6 & 5.3 & 2.1 \\
\hline Glass & 5.5 & 1.5 & 2.6 & 3.7 & 3 & 1.8 & 2.6 \\
\hline Others & 1.9 & 8.4 & 10.4 & 18.2 & 15 & 25.74 & 1.8 \\
\hline Total & 100 & 100 & 100 & 100 & 100 & 100 & 100 \\
\hline
\end{tabular}

According to CAP (2010) they observed that much of leftovers foods are from fast food eateries, coffee shops, and food courts, restaurants and even in at individual households in Malaysia. At most of the government functions, leftover foods were not eaten at birthdays and wedding receptions. The Government agencies and companies should always be mindful on the amount of food served at official and corporate functions. Some restaurants should find means such as fining those who have leftovers on the plates. Though, this could backfire as consumers may avoid eating in such restaurants which could affect the income of their business. However, a notice such as this restaurant is green conscious and does not tolerate wastage as there are many who could live on the wasted foods could send the right message to would be customers to change their behaviour towards food wastes.

Women according to findings have a greater tendency to waste food as they are more concerned about their calorie intake from what restaurant owners found. Furthermore, many of the bigger restaurants are guilty of food wastes because of their respective policies; they do not allow leftover foods to be taken away by their employees. From findings, much of the unconsumed food comes from restaurants. Furthermore, Lily Zakiah et al. (2005) found from their food wastes composition study, vegetable was the most wasted food items, while the females wasted significantly higher than males for all meals. This finding is similar to that of Koivupuro et al. (2012) that single women generate more avoidable food wastes than their male counterparts. The reasons found contributing to plate waste at home ranges from food size, appetite, appearance of food, and temperature of foods and the time foods was served were factors found significantly contributing to food waste. Food waste from plate waste in Malaysia mostly occurs during dinner, and constitutes $53.2 \%$ and breakfast at least 31.3\% (Lily Zakiah et al., 2005). Plate waste is a proportion of edible portion of food served that was discarded at home or eats out during meals.

From the religious point of view, Muslim restaurant owner claims that wasting food is considered to be dosa (sinful) among Malays and Muslims. This is not different from the perspective of Christianity on food wastage as well. Jesus prohibited food wastage in the Holy Bible. Jesus commanded His followers after feeding five thousand people with only two pieces of fish and five loaves of bread to collect all leftovers, which was one of the miracles recorded in the Bible. He told His followers, "less there are no wastes of foods" John 6:10-12, which clearly shows that wasting food is socially wrong and unaccepted by all faiths.

However, despite this wastage in Malaysia, previous studies have shown that people in food insecurity according to Zalilah and Ang (2001) in urban low-income households indicated prevalence of overall food insecurity was higher (66.6 and $65.7 \%$ ) than $58 \%$ reported in the rural low-income communities where their studies was conducted. Food insecurity has been shown to affect the health 
and nutritional status of individuals, particularly women and children and the elderly (Adams et al., 2003; Kaiser et al., 2002; Alaimo et al., 2001). The objectives of the study are to understand the impacts of food waste and the need to use edible food wastes generated on daily basis by households, restaurants and hotels to reduce food insecurity among the poor households the low income earners, the homeless and its social impacts in Malaysia through applying household food security survey module.

\section{Methods and materials}

Data from this study was taken from secondary sources on food wastes, such as literatures on global food wastes situations and food security, food wastes food security studies in Malaysia, and from the Ministry of Housing and Local Government (MHLG). The study is divided into eight parts. The first part is the introduction of the study followed by food wastes in Malaysia. The third part is the methodology and the fourth part of the study looked at the impact of food wastes and climate change on food security in general. This was followed by Malaysia policy plan on food security in 2008 world financial crisis and the measures to identify those in food insecurity as parts four and five respectively. There was household's food security module which forms parts seven. And lastly the way forward which is the conclusion of the study.

\section{The impact of food wastes and climate change on food security}

The impact of food waste on food security from climate change is alarming and this is observed by UN Secretary General. In all the efforts geared towards mass food production, however, government in trying to achieve food security for the people should also understand that food security, climate change and food waste go hand in hand or have linkages. Because according to Ban Ki-Moon, former UN Secretary General, in November 2009 he said that "there can be no food security without climate security." Food waste generates greenhouse gas which leads to climate change and affect food production. This is recognized by the international community, food security without climate security in meaningless and defeats the aim of sustainable food consumption (Ki-Moon, 2009). Recently, the Commission on Sustainable Agriculture and Climate Change Beddington et al., (2012) recommended reduction of food waste at households and in the food system as one of the ways of achieving food security in the face of climate change. Food wastage creates lots of environmental problems resulting in more reducing irreversible resources, creating waste and pollution which surpass the earth's capacities to take in and adapt them, and therefore leading to deterioration of resources like soil, water, and destruction of jungles which has accelerated flood, reduce food production and threatens our ecosystems as well (Vries and Riele, 2006).
These days the reason why we are facing serious problems due to environmental pollution and resource scarcity is because of unsustainable food consumption and wastage of food at households. This is because according to findings $30-40 \%$ of environmental degradation was as a result of consumption activities of households (Grunet, 1993). Food waste are not utilized sustainably as a resource either to feed those in the food insecurity or to enhance future production; The fact is that till a decade back, we have laid more importance to production and consumptions only, but ignoring its impact on environment. In the words of Schumacher he sums it up with these words, "The most fateful errors of our age are the belief that the problem of production has been solved. This illusion is mainly due to our inability to recognize that the modern industrial system, with all its intellectual sophistication, consumes the very basis on which it has been erected. To use the language of the economist, it lives on irreplaceable capital which it cheerfully treats as income" (Schumacher, 1973). This is a clarion call for people to change their behaviour on consumption. The attention to reduce food waste should include public education through creating awareness of food waste threat on our quest for uninterrupted food security, and better management of food at home and as well making food waste socially unacceptable right from cradle age.

\section{Malaysia policy plan on food security in 2008 world financial crisis}

During the food crisis of 2008, Malaysia adopted various policies to cushion the effect of the food crisis, such as providing cash subsides for paddy rice producers to stimulate rice productions (Arshad and Abdel Hameed, 2010). But there was no issue of looking at the high wastage of foods at household. Though, this strategy received some bad assessment by some economist who saw it as not sustainable, however it did helped minimized the impact of the food crisis at that particular period. New rice growing areas in Sabah and Sarawak was developed to boost rice production. Also, price control or ceiling price was peg on some agriculture product to reduce inflations and the effect of the crisis, such as prices at farm and retail levels respectively. However, there was no policy on food wastes when all these measures were taken to reduce food insecurity with edible food wastes as it might not be seem to be a crucial issue. But with high rising cost of foods and removal of food subsidy on some food items lately by Malaysian government, I think this is the right time for households to start having a rethink of how they could manage their food inventory properly well to avoid incurring wastage. As the quantities of edible food wastes at households, public function and even in food industries are affecting food security, as these could be used in part to reduced wastage and channel it for good use. Table 2 shows Malaysia's self-sufficiency food level. 
Table 2: Malaysian's self-sufficiency level in food commodities 2000-2010 (\%)

\begin{tabular}{cccc}
\hline Commodities & 2000 & 2005 & 2010 \\
\hline Rice & 70 & 72 & 90 \\
Fruits & 94 & 117 & 138 \\
Vegetables & 95 & 74 & 108 \\
Fisheries & 86 & 91 & 104 \\
Beef & 15 & 23 & 28 \\
Mutton & 6 & 8 & 10 \\
Poultry & 113 & 121 & 122 \\
Eggs & 116 & 113 & 115 \\
Pork & 100 & 107 & 132 \\
Milk & 3 & 5 & \\
\hline \multicolumn{4}{c}{ Source: Wong (2007) }
\end{tabular}

Malaysia in 1998 imported food worth of RM10.52 billion; this is very surprising, because this figure is very high considering that Malaysia is a small country, especially how this figure increased within eight years. Yet nobody could account for these high food importations the amount that was unconsumed and wasted at homes. From 2002 to 2004 food imports were more than food exports resulting in food imports deficit, from RM4.9 billion to RM6.6 billion which does not augur well for the economy of a country aiming to eradicate core poverty come 2020 . There is need to understand the factors that influences food waste generation which could support solutions towards a reduction of waste, improvements in food security, and in turn the protection of the environment. The understanding of these factors that influences food wastes generation could help to change people's perception and behaviour, thereby reduction food waste impacts on food security.

No country should depend more on importation of food as it could seriously affect food security when the exporting countries impose import restriction as in the 2008 global food crisis. This situations made the Malaysian Minister of Agriculture and Agro Based Industries then raised alarm saying through during his visit to China that there was a trade deficit of RM5 billion in the country's imports bills from his findings. It is indeed a very high figure for a country that has all along been agriculture-based, where 35\% of total land area, or 11.63 million hectares, is suitable for agriculture. Malaysia's main imports are cereals, dairy products, vegetables and fruits (Wong, 2007). Malaysians also consume about 2.4 million tons of rice per year (mtpy) and 30\% of most this were imported from neighbouring country Thailand. This is a worrying trend as most parts of these unconsumed foods could have been wasted at households yet people think there are abundant storage of foods in time of crisis as wasting foods has become the habits of most households.

Furthermore, during the world financial crisis, due to the concern on food security, the situation prompted many households' to change behaviour on buying and waste of food. Quite good number of households started reducing food wastage and became very thrift in consumptions and avoided unnecessary food wastage because food prices was sky rocking daily, and food that would have otherwise thrown away during the time of abundance became the most sort after by households. It seems therefore like increasing food cost as suggested by some literatures could be the solution to food waste!. Notwithstanding, it is not a good idea as this will be making life more difficult for the citizens and have negative social effect in the long run. In those days, difficult periods, food budget of households were often the first part of expenses to cut off during adjustment of what household should when there is food insecurity. In fact, most at times, the nutritious quality of such food is lost as households resort to buying cheaper foods as food cost increase and other household expenditure costs affect the amount of money available for food (Babbington and Donato-Hung, 2007; Kirkpatrick and Tarasuk, 2007). The inability to understand these food waste challenges could pose as serious threat for sustainable food security system in Malaysia. The Table 3 shows food imports and exports in Malaysia for the years 2002 to 2004.

Table 3: Food import bill (RM Billion)

\begin{tabular}{cccc}
\hline Imports & 2002 & 2003 & 2004 \\
\hline Food imports & 12.43 & 12.77 & 16.64 \\
Food exports & 7.49 & 8.44 & 10.03 \\
Net imports & 4.94 & 4.33 & 6.61 \\
\hline & Source: Wong (2007)
\end{tabular}

Foods industries have very crucial to play in this bid to reduce food waste by applying the best practice so that waste will be minimize. Solving the world's food insecurity problem is not simply by producing more food but rather minimizing food waste at every level especially households. There should be a reduction in food wastage in EU countries and developed world and as well in food storage and transport in the developing regions of Africa. Though, it is quite obvious that some parts of food wastes are inevitable, but when food wastes are reduce it will go a long way in reducing quantities of wastes that goes to landfills and its impact in future global food security and the sustainability of agricultural product.

\section{Measures to identify those in food insecurity}

In a world where soaring cost of living and withdrawal of subsidies on some essentials goods has drastically affected food budget of many households. Identifying those who are within the food insecurity level for assistance might be an uphill task considering the economic situations currently been witnessed by many households. This is because the researcher could recall a scenario that happened when he worked with World Bank assisted housing project in one of the developing countries many years ago. This housing project was meant for low income earners within certain salary scale bracket to own personal houses. However, this program was hijacked by higher income earners, whom on filling applications forms lower their annual income so that they could be qualified as beneficiaries of this scheme. Therefore, the aim of the project was defeated; in this regard identifying those who fall 
within the food insecurity should be a priority so that the aim could be achieved. With the advancement in information technology where workers salaries pay slips are printed out for them. This should help in identifying those that really needs assistance with the large quantities of edible leftover food disposed daily by affluent Malaysians.

It is important to establish methods and tools to regularly monitor these other aspects of food security, and thus be able to use the information to inform support services, practices and preventive action as well for a sustainable consumption (Coleman-Jensen et al., 2015). By applying households' food security survey module (HFSSM), this could be a useful measure to identity those who are really in need for assistance with edible food waste from difference sources in Malaysia. This could help reduce food insecurity partly from the low income earners among Malaysia populace who truly need food assistance with edible food wastes.

Malaysia government having seem the need to reduce food waste has sort assistance from the Ministry of Environment Japan (MOEP) and as well experts from Institute for Global Environmental Strategic (IGES) for the national strategic plan primarily focused on food waste management with emphasis on the 3R (Reduce, Reuse and Recycle). This is to help in assisting and addressing the challenges of the entire food waste management system and its impact on food security MHLG (2010). The national draft strategic plans stipulates the roles and strategies to be implemented by different players which are the mainly the for the macro food waste generators such as hotels, restaurants and food industries in Malaysia. But the issue of households' food waste which generates far more waste than these macro sources put together was not in the picture. It should be made clearly to that when households are made to understand their unsustainable food consumption have both environmental and economic consequences and affect food security of other poor fellow citizens who are in food insecurity, food waste at restaurants and hotels will surely be reduced The general strategies to reduce food waste is shown in Fig. 1 while the edible food show be channeled to those who needs it while it is still in good condition.

\section{Household food security survey module (HFSSM)}

The Household food Security Survey Module (HFSSM), an 18 item tool (with eight questions relating to children in the household), is a comprehensive measurement tool that can determine food security status as well as severity ranging from anxiety because food will not be enough for the family, and to children having nothing to eat the whole day. It consists of 18 items questions asking about their food security condition for the past 12 month's period. The questions are specified such like lack of money or ability to not being able to access food is the reason for their condition. In the 18 questions, ten are specified for adults with regards to their experience or for the households in general (adult scale) and the remaining eight are specified for children less than 18 years (child scale) in the household (ColemanJensen et al., 2015).

The HFSSM has been used regularly in the USA to measure food insecurity and was found that 14.7 percent of US households reported being food insecure in 2009 and even in Australia. This can be replicated in Malaysia to determine families who are in the food insecurity bracket for assistance as the government aims towards adequate food access to all her citizen and wipe out core poverty in Malaysia, while the inedible food wastes could be used for composting and bio waste.

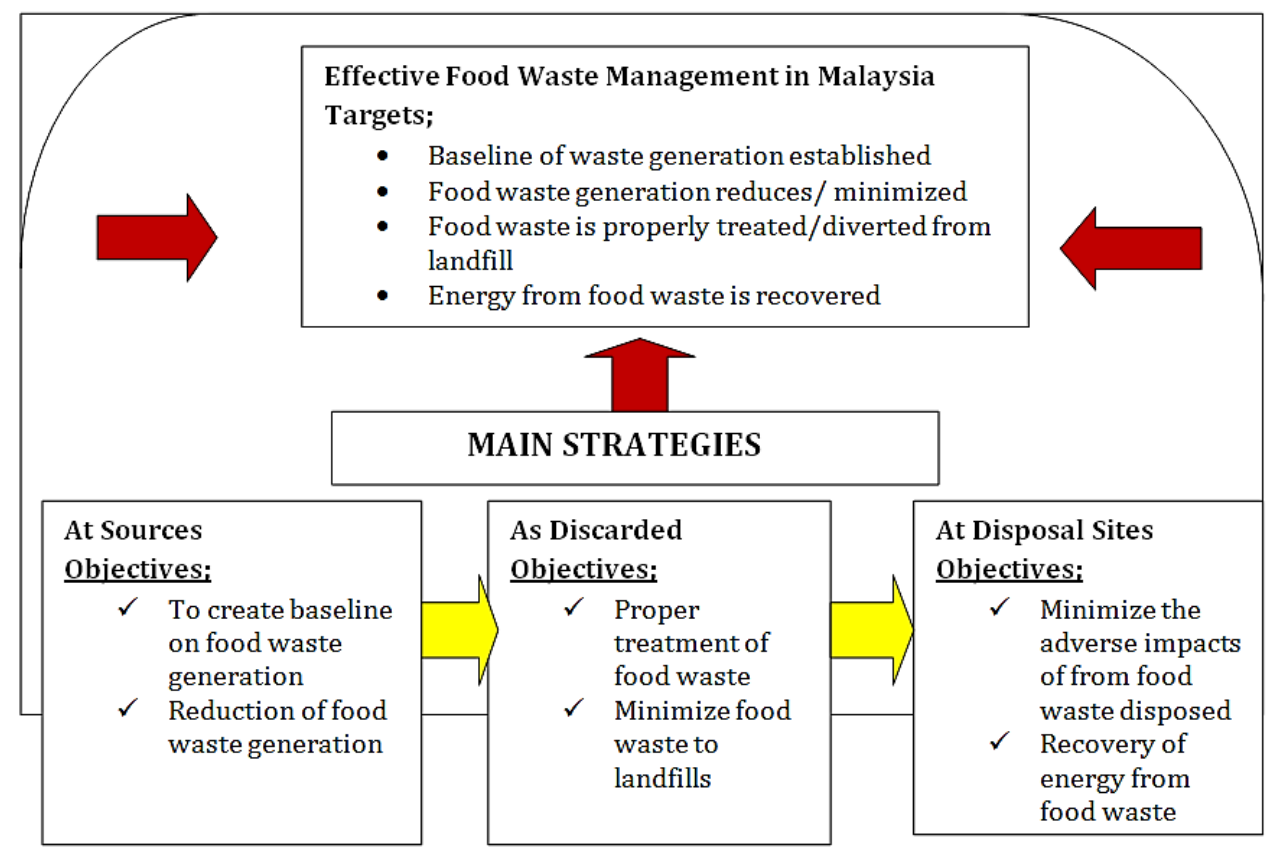

Fig. 1: National strategic plans for food waste management (MHLG, 2010) 
There is no point for food wastage while there are many who are disadvantaged and are likely to be food insecure. But food insecurity may also be present in those with poor health, limited physical function and limited physical access to food outlets. Monitoring the health qualities of edible food waste needs to be incorporated into any national food policy in order to ensure the affordability and availability of foods required for a healthy diet in all parts of Malaysia. Some of the healthy food basket surveys in some other countries have shown evidence of differences in prices and availability between urban, rural and remote regions which can be used for developing appropriate support systems for those areas incurring higher food prices (Burns and Friel, 2007).

In Malaysia HFSSM survey may not be very popular, but by applying it could help to identify how many percentage of the population falls within these categories to be assisted with large quantities of edible foods discarded daily by most affluent Malaysians and some cooperate bodies. Those in food insecurity in Malaysia could be in low in number compare with her neighboring countries, considering efforts the government has put in place and still doing to reduce food insecurity among low income Malaysians. The high number of migrant workers from neighboring regions looking for greener pasture in Malaysia could attest to this fact that Malaysia is rich in food supply. Thus, it could be right say that Malaysians do not much food problem but rather food wastes problem (Jereme et al., 2016). As prepared and freshly cooked food could easily be obtain at every corner of the cities. Therefore, there is need to change the behaviour of Malaysia towards food wastage as it is not even tolerated in far more richer, developed and industrialized countries like Germany. As citizens in this country are made to understand that resources such as water, energy, labour used to produce wasted food belongs to the people and food waste has negative impacts on the natural environment. This is the message the Malaysian government should always disseminate to all her Malaysian both you and old, resources to produce foods belongs to the people, and therefore there is no reason to waste food.

\section{Conclusion}

The Way forward: Malaysia is an affluent nation; this is a fact that cannot be disputed. Although costs of living have increased especially foods, due to global economic problem, even with that, food wastes still outstrip other households waste during waste composition study by local authorities. However, even though foods are in abundance, there are still some households who are in food insecurity and lack adequate food and dwells mainly in the squatters' areas of the cities and in the rural areas with low income.

A periodic conduct of household food security survey module (HFSSM) will enable the government to understand those who fall into this category of households, and how they could be assisted with edible food waste received from effluents households and restaurants, food banks and food industries. This module has been used successfully in the United States of America and Australia. This can be replicated in Malaysia to determine families who are in the food insecurity for help as the government aims towards adequate food access (food security) to all her citizens and eliminate core poverty among households as Malaysia match towards a developed nation status.

Encouraging households, restaurant owners and hotel food outlets to donate their edible food wastes to food banks for those in need of it is a simple way to reduce food insecurity in Malaysia. But this could be possible where there are provisions of facilities such as food banks in nearby areas just like there are recycling centers built in some local areas and creating awareness through the mass media on the need to reduce food wastes. Awareness on waste reduction currently is mostly centered on paper, plastic and scrap metals but not on food wastes. It is very rare to see on the local medias were by the problems of food waste is highlighted or discussed. This should change, there should be aggressive media campaign against food wastes and it impacts on the environment before households could understand the need to reduce food wastes, Emphasis to reduce food waste is still very limited and a challenge that should be taken by every Malaysian as there are many in food insecurity that could feed on wasted foods. Furthermore, edible food waste donors could be given tax rebate based on the total price of the foods donated monthly or yearly as the case may be. By giving this incentive, thus it could spur households and organizations to always give out edible food wastes to designated food banks to be distributed to those in food insecurity. Therefore, Food banks should be established in residential and strategic areas for easy access for those who want to donate edible food. The inedible food waste could be separated and use as compost for agriculture purpose or for animals feeds. Besides it could be used as biogas to generate energy. This is currently done in developed countries like UK and US. As larger percentages of municipal solid wastes in Malaysia are organic wastes, if separated it could help to reduce cost of waste management for local authorities and its associated environmental impacts such as landfill emissions which is an agent of climate change.

\section{Acknowledgement}

The authors wish to appreciate the (High Potential Centre of Excellence) Institute of Environment and Development, (Lestari) Universiti Kebangsaan Malaysia for the financial support provided for this work under the Research University grant code: AP-2014-017 and GUP-2015050 . 


\section{References}

Adams EJ, Grummer-Shawn L, and Chavez G (2003). Food security is associated with increased risk of obesity in California women. The Journal of Nutrition, 133(4):1070-1074.

Agamuthu P (2011). 930 tonnes of food being thrown away every day. Available online at: http://repository.um.edu.my/13951/

Alaimo K, Olson CM, and Frongillo EA (2001). Food insufficiency and American school-aged children's cognitive, academic, and psychosocial development. Pediatrics, 108(1): 44-53.

Arshad FM and Abdel Hameed AA (2010). Global food prices: Implications for food security in Malaysia. CRRC Consumer Review Report No. 119073, Research in Agricultural and Applied Economics: 21-38. Available online at: http://purl.umn.edu/119073

Babbington S and Donato-Hunt C (2007). When there isn't enough to eat: The food insecurity of ANGLICARE Sydney's emergency relief clients in Wollongong. Full Report of the Pilot Study, Sydney, Australian.

Beddington JR, Asaduzzaman M, Fernandez A, Clark M, Guillou M, Jahn M, Erda L, Mamo T, Bo NV, Nobre CA, and Scholes R (2012). Achieving food security in the face of climate change. Final Report from the Commission on Sustainable Agriculture and Climate Change, CGIAR Research Program on Climate Change, Agriculture and Food Security (CCAFS), Copenhagen, Denmark. Available online at: https://ccafs.cgiar.org/ commission

Burns C and Friel S (2007). It's time to determine the cost of a healthy diet in Australia. Australian and New Zealand Journal of Public Health, 31(4): 363-365.

CAP (2010) Make food wastage a punishable crime. Consumers Association of Penang, Penang, Malaysia. Available online at: https://www.consumer.org.my/index.php/food/security/15 5-make-food-wastage-a-punishable-crime

Chuah KH (2011). Sustainability Development through Energy Efficiency Initiatives in Malaysia. In the $15^{\text {th }}$ International Conference on ISO \& TQM (ICIT'11), Universiti Tenaga Nasional, Kajang, Malaysia

Coleman-Jensen A, Rabbitt MP, Gregory CA, and Singh A (2015). Household food security in the United States. United States Department of Agriculture (USDA), Washington, USA.

FAO (2007). Global food security under climate change Proceedings. Food and Agriculture Organization, Rome, Italy.

Grunet SC (1993). Everybody seems concern about the environment but is this concern reflected in (Danish) consumers food choice?. European Advance in Consumer Research, 1: 428-433.
Gustavsson J, Cederberg C, Sonesson U, van Otterdijk R, and Meybeck A (2011). Global food losses and food waste. Food and Agriculture Organization of the United Nations. Rome, Italy.

Jereme'IA, Siwa C, Begum RA, and Talib BA (2016). Addressing the problems of food waste generation in Malaysia. International Journal of Advanced and Applied Studies, 3(8): 68-77.

Kaiser LL, Lamp CL, Johns MC, Sutherlin JM, Harwood JO, and Melgar-Quiñonez, HR (2002). Food security and nutritional outcomes of preschool-age Mexican-American children. Journal of the American Dietetic Association, 102(7): 924-929.

Ki-Moon B (2009). United Nations; Opening remarks at food security summit Rome, 16 November 2009. Available online at: http://www.un.org/en/issues/food/taskforce/stmt.shtml

Kirkpatrick SI and Tarasuk V (2007). Adequacy of food spending is related to housing expenditures among lower-income Canadian households. Public Health Nutrition, 10(12): 14641473.

Koivupuro HK, Hartikainen H, Silvennoinen K, Katajajuuri JM, Heikintalo N, Reinikainen A, and Jalkanen L (2012). Influence of Socio-demographical behavioural and attitudinal factors on the amount of avoidable food waste generated in Finish households. International Journal of Consumers Studies, 36(2):183-191

Lily Zakiah MD, Saimy I, and Maimunah AH (2005). Plate waste among hospital inpatients. Malaysian Journal of Public Health Medicine, 5(2): 19-24.

Loo TE (2011). Trashing bad habits. Available online at: http://www.thestar.com.my/news/education/2011/12/25/t rashing-bad-habits/

MHLG (2010). Development of a national strategic plan for food waste management in Malaysia. National Solid Waste Management Department, Ministry of Housing and Local Government, Kuala Lumpur, Malaysia. Available online at: http://docplayer.net/storage/61/46339688/1491116000/6 OeqnSmGm028qrhBU5oS-A/46339688.pdf

Schumacher EF (1973). Small is beautiful: A study of economics as if people mattered. Blond and Briggs, London, UK.

Vries JL and Riele HR (2006). Playing with Hyenas: Renovating environmental product policy strategy. Journal of Industrial Ecology, 10(3): 111-127.

Wong LCY (2007). Development of Malaysia's agriculture sector: Agriculture as an engine of growth. In the ISEAS Conference on the Malaysian Economy: Development and Challenges, ISEAS Singapore, Singapore, Singapore: 1-21.

Zalilah MS and Ang M (2001). Assessment of food insecurity among low income households in Kuala Lumpur using the Radimer/Cornell food insecurity instrument - A validation study. Malaysian Journal of Nutrition, 7(1-2): 15-32. 